\title{
O Paradigma Weberiano da Ação Social: um Ensaio sobre a Compreensão do Sentido, a Criação de Tipos Ideais e suas Aplicações na Teoria Organizacional
}

\author{
Lúcio Flávio Renault de Moraes \\ Antonio Del Maestro Filho \\ Devanir Vieira Dias
}

\section{Resumo}

Este trabalho foi elaborado com o propósito de resgatar e compreender o elo de ligação existente entre o pensamento weberiano e a teoria das organizações ocidentais, fortemente influenciadas pela ética capitalista. Apresenta as conexões causais e os tipos ideais e seu respectivo papel na elaboração de instrumentos de pesquisa em ciências sociais. A teoria weberiana considera as organizações como sistemas burocráticos, que constituem o ponto de partida para sociólogos e cientistas políticos no estudo das organizações. O trabalho aborda também a sociologia compreensiva da ação social e apresenta as características positivas e negativas da burocracia. Enfatiza ainda a dominação ideológica do capitalismo, que vem sendo cada vez mais reforçada pelos programas de treinamento e desenvolvimento nas empresas.

Palavras-chaves: pensamento weberiano; tipos ideais; burocracia; teoria organizacional; hermenêutica.

\section{Abstract}

This paper is concerned with recovery and comprehension of the linking between Max Weber's thought and the Organizational Theory. It outlines the causal connections of ideal types as research's instruments in social sciences. The theory considers the organizations as bureaucratic systems, which are the departure's point for sociologists and politic scientists on the Organizational Studies. It approaches the comprehensive sociology of the social action and show's the both sides of the bureaucracy with the positive and negative characteristics. So, it emphasizes also the ideological domination of the capitalism that has become very stronger in the training and development programs of the human resources.

Key words: Weber's thought; ideal types; bureaucracy; organizational theory; sense making. 


\section{INTRODUÇÃO}

Este trabalho foi elaborado com o propósito de resgatar e compreender o elo de ligação existente entre o pensamento weberiano - construído à luz de debates travados naquela época entre os defensores da corrente positivista até então dominante e críticos da natureza das ciências do espírito, quanto ao papel dos valores e possibilidades de formulação de leis - e a teoria das organizações ocidentais, fortemente influenciadas pela ética capitalista. O paradigma da ação social pode ser estendido para todas as áreas das ciências humanas e, especificamente, para as ciências administrativas, considerando que a própria ação humana decorre de dois fatores (variáveis): os valores e os fins (objetivos).

Na obra de Weber (1984) destacam-se duas matrizes de estudo, a neokatiana e a nietzschiana, onde a categoria da ação, embora complexa, demanda análise mais cuidadosa dos aspectos relativos à vontade humana, desejos humanos, razão (entendida como a eleição de fins e meios) e, finalmente, as motivações humanas (tidas como irracionais) aliadas às tradições sociais.

Além de introduzir as idealidades, Weber (1979) utiliza a hermenêutica, embora não mencione o termo, substituindo-o pela sociologia compreensiva, por meio da qual busca a interpretação do sentido da ação social sintetizada no método de interpretação, no qual estão unidas a compreensão e a explicação dos fenômenos sociais.

Ao identificar os tipos ideais, Weber (1979) dá a conhecer e a compreender os aparatos ideológicos que perpetuam e justificam a racionalidade no capitalismo ocidental, retirando o véu que ocultava as relações e comportamentos dos indivíduos no interior das organizações (teoria da burocracia, formas de dominação, formas do protestantismo etc). Nas conclusões finais serão abordados rapidamente alguns temas atuais discutidos com veemência no campo da administração que, no nosso entendimento, podem ser interpretados pelo método hermenêutico, à semelhança dos estudos weberianos, objetivando compreender o seu sentido e até, quem sabe, no campo das novas tecnologias gerenciais, sugerir a construção de tipos ideais que possibilitem a explicação de novas formas de dominação hoje tão presentes nas organizações ditas modernas, camufladas sob a égide de técnicas de gestão e reforçadas pelo caráter ideológico da ação de treinamento e desenvolvimento de recursos humanos. 


\section{Aspectos Gerais da Obra de Max Weber}

Max Weber, ao lado de Émile Durkheim e Karl Marx, constitui-se num dos grandes expoentes da sociologia moderna. Weber viveu na época dos grandes debates travados entre os defensores do positivismo, que dominavam os meios científicos, e os seus críticos. O cerne das discussões estava na caracterização das ditas ciências da natureza e sua diferenciação em relação às chamadas ciências do espírito (históricas, sociais, culturais) ou humanas. Outro aspecto importante naqueles debates consistia na definição do papel dos valores e na possibilidade da formulação de leis que pudessem ser aplicadas nas ciências humanas.

Weber procurou construir um esquema interpretativo fundamentado na neutralidade axiológica, ou seja, buscou construir uma ciência social sem pressupostos. Preocupado com o problema da ação, desenvolveu o conceito de ação social significativa, tendo como ponto de partida o indivíduo. Assim, definiu a sociologia como a ciência da ação social, estruturando os níveis da ação em três tipos básicos: (1) ação frente a uma situação concreta; (2) ação prescrita com base em regras determinadas; (3) ação decorrente da compreensão informal das regras. Para a análise dos valores, Weber fundamentou-se em Rickert (1943), objetivando distinguir juízo de valor da relação de valor, possibilitando-lhe demarcar os limites e a área de pesquisa nas ciências sociais. Weber acreditava que a explicação causal pudesse chegar a conclusões de validade universal. Por sua vez, Rickert (1943) não considerava o mundo dos valores como portador de caráter absoluto e objetivo, centrado na ação humana que o realiza como resultante de sua práxis. Na captação do sentido da ação social, Rickert (1943) sustentava que cada indivíduo constrói sua personalidade, define e decide seu destino, ou seja, define uma causa ou ideal a que se dedica, à semelhança da criação do valor preconizado por Weber no ato da escolha. Weber desenvolveu o conceito de ação social significativa a partir do indivíduo, sendo este conceito estendido às instituições como Estado, empresa ou sociedade anônima, que se transformam em palcos onde a ação é desenvolvida.

Ao abordar a ação social, Weber (1979) utilizou construções de tipos ideais despidas de sentido histórico, porém solidamente concebidas no que se refere à elaboração dos conceitos e fundamentadas no desencanto do mundo e na busca e produção de um sentido (sensemaking). Estes construtos, adequados à realidade, criam a possibilidade de aplicação teórica e prática. Na sua obra Weber (1979) substituiu a razão universal pela contingência histórica, na qual a história aparece com sentido variável em função do sujeito da ação, cuja coerência estabelece que o mundo dos valores é infinito e cabe ao homem escolher seus valores. $\mathrm{O}$ 
grande destaque weberiano consistia na compreensão da flutuação do sentido que, adicionada à ação, fundamentava a sociologia compreensiva (método hermenêutico).

Ao estabelecer o método de interpretação da realidade social, Weber uniu compreensão e explicação, emergindo daí a decifração do sentido da ação. Para o autor, o campo de estudo da sociologia deve ser definido segundo as formas sociais e nunca por meio de conteúdos, o que o leva a realçar os indivíduos, comportamentos e ações, independentemente da necessidade de um conhecimento universal e de um sistema de valores. A ciência acompanhada do desencanto é, para ele, uma das manifestações da vida. Ao estabelecer uma estrutura lógica de análise, ele classifica a racionalidade em formal e material. Para Weber o racional e o irracional são encarnações da razão racionalista, isto é, são os lados da mesma moeda, os opostos complementares. Daí decorrer a possibilidade de mudar o racional, abstraindo-se da razão. No caso da ciência, esta afirmação fica clara, na medida em que a exclusão dos juízos de valor de seu contexto só justifica a eficácia de seus meios e não fundamenta, necessariamente, a legitimidade de seus fins. Segundo o autor se, por um lado, a ciência ensina ao homem formas de utilização racional dos meios e sua respectiva escolha para atingir os fins desejados, por outro lado, exclui qualquer juízo de valor com relação à sua legitimidade e racionalidade.

Ao privilegiar o predomínio da razão racionalista, Weber cristaliza a visão existente na realidade, que é reforçada pela separação entre ciência natural e cultural (compreensiva). É importante lembrar que, para Weber, a história não representa o processo da razão triunfante e sim a oposição razão-não razão, em freqüente tensão, constatação esta inspirada nos estudos de Dilthey (1994), considerado um dos mais importantes representantes da facção contrária ao positivismo. Este autor contrapôs à razão científica, defendida pelos positivistas, a razão histórica, que pressupõe a recuperação do sentido sempre atrelado temporariamente e ligado a uma visão de mundo e a um ponto de vista. Entretanto, foram Karl Marx e Friedrich Nietzsche que chegaram a ser reconhecidos pelo próprio Weber como importantes pensadores de sua época, aqueles que influenciaram de forma relevante a obra daquele sociólogo.

No caso de Marx, a identificação da influência deve-se ao compartilhamento do tema relativo ao capitalismo ocidental, que se tornou objeto de estudo por parte de ambos, dentro de uma perspectiva histórica, econômica, sociológica e ideológica. Outro aspecto convergente entre os dois estudiosos consiste na proposta feita por Weber, quando pretendeu verificar a capacidade que teria o materialismo histórico de encontrar explicações adequadas à história social e, em particular, no que se refere às relações entre a infra-estrutura e a superestrutura. 
Com efeito, Weber procurou compreender de que forma as idéias, bem como os fatores de ordem material, cobravam força na explicação sociológica, apesar de imputar críticas ao monismo causal considerado como uma das características marcantes do materialismo marxista, examinado nas suas causas mais vulgares. A herança da percepção de Nietzshe também se faz presente na obra weberiana (1980), na medida em que ele concorda com a afirmação de que a vontade de poder, manifestada na luta entre valores e idéias antagônicas, constituía chave para a compreensão da realidade social, política e econômica. É importante lembrar que este fato refletia as preocupações de historiadores, sociólogos e psicólogos alemães contemporâneos de Weber, todos eles preocupados e interessados pelo conflituoso, presente de forma implícita no chamado pluralismo democrático. Foi, entretanto, o gênio original de Weber que avançou metodologicamente na questão da racionalidade. Ele interpretou o desenvolvimento histórico do ocidente como conseqüência da marcha evolutiva da racionalidade. Sempre afirmou seu racionalismo, nunca procurou uma terceira via para conciliação entre idealismo e materialismo. Conforme menciona Tragtenberg (1980), “em Weber reflete-se a crise ideológica da consciência social burguesa. É uma reação lúcida à quebra da razão, àqueles que preferem fazer o sacrifício do intelecto, para o qual as velhas igrejas estão misericordiosamente abertas”.

A obra de Weber é caracterizada pela polêmica, se se considerar que a realidade social é contraditória. Assim, ao proceder-se uma reflexão intelectual sobre sua obra, com certeza estará também presente, nesta reflexão, a contradição. A contradição fundamental na obra de Weber está evidenciada nos seus postulados metodológicos derivados do neokantismo e sua sociologia das formas de dominação, na qual emerge a sombra de Marx.

Weber foi o criador da sociologia da religião, vinculando a ação religiosa a diferentes estamentos e classes, terminando por considerar a religião como elemento de legitimação do poder e de domesticação das massas. Metodologicamente, pode-se dizer que Weber se aproxima do idealismo filosófico. Por outro lado, quanto ao aspecto da análise ética das religiões, poder-se-ia dizer que ele se aproxima do idealismo histórico. No plano político, considerando a sua busca por uma elite à altura da Alemanha da sua época, e levando em conta a sua vocação política, oriunda de uma burguesia sem capacidade de exercer o poder, pode-se dizer que ela acentua o idealismo político.

Na obra de Weber, o indivíduo constitui a unidade explicativa, tornando-se ponto de partida e de chegada. Os conceitos sociológicos são elaborados (compostos) pouco a pouco e seus componentes são retirados da realidade histórica; assim, o processo do conhecimento fundamenta-se no indivíduo. 


\section{O Método Weberiano de Estudo da Ação Social}

\section{A Sociologia Compreensiva de Weber: o Estudo da Ação Social e do Sentido}

Para Weber (1979) a sociologia é a ciência que pretende entender a ação social, interpretando-a, e busca explicá-la causalmente em seu desenvolvimento e efeitos. Segundo Colliot-Thélenè (1995) “a compreensão da ação social, longe de constituir um simples elo da exemplificação causal, é o método específico da sociologia, que daí extrai, por essa razão, sua denominação”.

Conforme Weber (1979), a sociologia deve ser compreensiva, porque seu objeto de estudo é a ação humana. A ação humana, por sua vez, possui uma característica especial, que demanda procedimentos mais abrangentes se comparados àqueles comumente utilizados pelas ciências da natureza, isto é, a ação humana é dotada de sentido e cabe ao cientista social metodizar a compreensão por meio da elaboração e do estabelecimento de conexões causais (esquemas), que possibilitem a decifração do sentido imaginado e subjetivo do sujeito da ação.

Ele afirma que a ação objetiva ao sentido e a hermenêutica passam a ser o método ideal na busca da resposta para a pergunta do sentido social da ação. Portanto a explicação sociológica busca compreender o sentido, o desenvolvimento e os efeitos da conduta de um ou mais indivíduos referida à do outro, não se propondo a julgar a validade de tais atos, nem a compreender o sujeito enquanto pessoa. A explicação é definida como sendo a captação e interpretação da conexão do sentido em que se inclui uma ação (Quintaneiro et al., 1999). Uma primeira classificação da ação social estabelecida por Weber levou em consideração a natureza da racionalidade segmentada em relação aos fins e valores envolvidos no processo desta ação. A ação social de um indivíduo ou grupo será entendida como racional em relação a fins se, para atingir um objetivo previamente definido, lançar-se mão dos meios adequados e necessários. É o caso de uma conduta científica ou de uma ação econômica (modelos típicos de ação que permitem uma interpretação racional).

De um lado, Weber afirma que a conexão entre fins e meios é tanto mais racional quanto mais se elimine a interferência perturbadora de erros e afetos que possam desviar seu curso. De outro lado, a ação social (conduta) será racional em relação a valores, quando o sujeito orienta-se por fins últimos, agindo em conformidade com seus próprios valores e convicções, mantendo sua fidelidade a estes valores que inspiram sua conduta ou, ainda, na medida em que acredita na 
legitimidade intrínseca de um comportamento válido por si mesmo. É o caso do cumprimento de um dever, de um imperativo ou exigência ditados por seu próprio senso de dignidade, por suas crenças religiosas, políticas, morais ou estéticas ou por valores nos quais acredita (justiça, honra, ética, fidelidade etc). Entretanto, cabe ressaltar que Weber deixava claro que o sentido da ação flutua demais, não se fixa; daí a possibilidade de existir certa racionalidade tanto maior quanto mais absoluto for para o sujeito da ação o valor que a inspira. Assim, o sentido da ação não se encontra no seu resultado e sim na própria conduta, como é o caso daqueles grupos que lutam em prol de valores considerados acima de qualquer outra coisa (movimentos ecológicos, paz mundial, exercício da liberdade etc).

A ação social pode ainda ser classificada tomando-se como referência a natureza da motivação. Nesta classificação temos as ações do tipo afetivo (sem qualquer motivação racional) e do tipo tradicional (determinada por costumes arraigados). Diz-se, portanto, que uma ação é considerada estritamente tradicional, quando hábitos e costumes arraigados levam a que se aja em função deles (como sempre se fez), tratando-se de uma reação a estímulos habituais. A ação de tipo afetivo é inspirada em emoções e medidas, tais como orgulho, inveja, desespero, vingança etc., e não leva em consideração os meios ou fins a atingir. Ao sociólogo compete a compreensão do sentido que um sujeito atribui à sua ação e seu significado social. Weber, entretanto, chama a atenção para o fato de que, muito raras vezes, a ação social está exclusivamente orientada por um outro dos tipos aqui classificados. Segundo ele, tais tipologias não passam de meros modelos conceituais puros.

\section{Os Tipos Ideais Weberianos e as Conexões Causais}

Para Weber (1979) obtém-se um tipo ideal acentuando unilateralmente um ou vários pontos de vista e encadeando uma multidão de fenômenos isolados, difusos e discretos, que se encontram ora em grande número, ora em pequeno número, até o mínimo possível, que ordenam certos pontos de vista escolhidos unilateralmente para formar um quadro de pensamento homogêneo. Assim, visando a dar aos conceitos utilizados pelo método histórico rigor suficiente, Weber criou a noção do tipo ideal, que designa o rol de conceitos que o especialista em ciências humanas constrói unicamente para fins de pesquisa.

O tipo ideal é outro momento de seleção utilizado pelo historiador e pelo sociólogo, na medida em que abandonem o real a partir de certos pontos de vista, em função da relação com os valores. Como não é possível a explicação de uma realidade social particular, única, por meio da análise exaustiva das relações causais que a constituem, uma vez que são infinitas, escolhem-se algumas delas por meio da avaliação das 
influências ou efeitos que delas se costuma esperar. O cientista social atribui a alguns desses fragmentos um sentido, destacando aspectos julgados importantes, baseandose em seus valores. A elaboração de um instrumento que sirva de orientação para o cientista social na sua busca pelas conexões causais, representa um trabalho muito valioso do ponto de vista heurístico. Este modelo (construto) nada mais é do que o tipo ideal, cuja finalidade é servir de baliza, de instrumento de colimação para o cientista se guiar, ao se enveredar na infinitude do real.

Desta maneira, o verdadeiro papel do tipo ideal é constituir-se num fator de inteligibilidade nos níveis da pesquisa e da exposição. Com relação à pesquisa, a construção de um tipo ideal permite ao cientista a formação de julgamentos de imputação causal que, embora não considerando aspectos qualitativos, serve de guia para a elaboração de hipóteses com base na imaginação fundamentada na experiência e disciplinada por um método rigoroso. No tocante à exposição, o tipo ideal não pretende, absolutamente, reproduzir a realidade, mas dotar a descrição de meios de expressão unívocos e precisos.

De modo geral, os tipos ideais possuem três características básicas que definem suas possibilidades e limites: (1) racionalidade (ou estrutura lógica) - quando são avaliados os meios e as conseqüências previsíveis, examinadas as condições que podem afetar o plano construído abstratamente sob a forma de tipo ideal da ação futura; (2) unilateralidade - permite dar rigor ao tipo ideal, por ser a condição ao mesmo tempo de amplificação dos traços característicos e da elaboração do quadro de pensamentos em conjunto coerente e não contraditório; (3) caráter utópico - o tipo ideal não é, e nem pretende ser, reflexo ou repetição da realidade.

O principal exemplo da aplicação do tipo ideal por Weber na sua obra é demonstrado na Ética Protestante e o Espírito do Capitalismo, onde ele parte de uma descrição provisória e vai definindo, gradualmente, ao longo da sua pesquisa, o que entende por espírito do capitalismo, para chegar ao conceito definitivo apenas no final do trabalho. Ele começa com uma inter-relação e termina com uma causa ação, afirmando que a ética protestante é o espírito do capitalismo.

\section{A Sociologia da Religião: o Ascetismo Secular (A Ética Protestante e o Espírito do Capitalismo)}

Uma das grandes preocupações de Weber consistia na compreensão das especificidades das sociedades ocidentais que levaram ao desenvolvimento do capitalismo. Ele afirmava que o capitalismo ocidental teria surgido por meio da racionalidade aplicada às empresas, à contabilidade, à técnica e ao direito, acrescida ainda da sua aplicação à vida, ideologia, ética e economia. A presença acentuada de empresários e trabalhadores qualificados protestantes nos países 
mais industrializados, sugeriu a Weber a possível existência de uma grande afinidade particular entre alguns valores identificados à época do surgimento do capitalismo moderno e a decantada ética calvinista. Assim, por meio de estudos e pesquisas nas obras de autores que representavam os valores aceitos e disseminados pelos calvinistas, ele se concentrou na identificação da relação existente entre uma ética religiosa, fundamentada na atividade incessante no mundo, e as condições ideais para o estabelecimento do capitalismo.

Com o intuito de fundamentar as conexões causais estabelecidas entre a mudança ocorrida na esfera religiosa e as transformações eminentes na economia, Weber apoiou-se nas publicações de Benjamim Franklin, no século XVIII. O trabalho passou a ser um valor em si mesmo, dignificador e enobrecedor do homem. Tanto o operário quanto o capitalista, detentor dos meios de produção, passaram a viver em função de sua atividade (trabalho) ou negócio e só assim possuíam a chamada sensação irracional da tarefa cumprida. O reino dos céus só seria atingido com o trabalho sem descanso pela vontade de Deus, glorificando-o por meio de suas atividades produtivas, que se tornaram um fim em si mesmas. Para Weber a adoção desta perspectiva ascética permitiu que os empresários pioneiros revertessem a sua imagem perante a sociedade e se tornassem heróis na nova ordem emergente. Ao avaliar uma entre as várias relações possíveis do ascetismo secular com a cultura contemporânea, Weber deixou claro que em nenhum momento teve a pretensão de contrapor-se ao materialismo histórico de Marx. O seu objetivo principal foi estabelecer e evidenciar as demais conexões causais que contribuíram para o desenvolvimento do capitalismo ocidental, utilizando um construto mental (modelo abstrato) ou tipo ideal que chamou de espírito do capitalismo (compreensão do sentido da ação social).

\section{As Relações Sociais: as Formas de Dominação}

A questão analisada por Weber quando constrói o tipo ideal relativo às formas de dominação, abrange o problema da continuidade das relações sociais, isto é, qual é a base de sustentação e manutenção da legitimidade destas relações, considerando que o social se origina no indivíduo e é manifestado pela ação individual. A resposta para esta questão encontra-se na base da organização social, estritamente ligada ao poder e à dominação, estudados por Weber em diferentes aspectos. Para ele, enquanto o conceito de poder é socialmente amorfo (não se limita a nenhuma circunstância social específica), a dominação está baseada numa probabilidade de obediência a um certo mandato. A dominação pode ser identificada por dois tipos de representação: (1) numa situação de monopólio, mediante uma constelação de interesses, como é o caso do mercado monopolista; (2) por meio da autoridade (poder de mando e dever de obediência), 
como é o caso do poder exercido pelo pai de família, pelo funcionário ou pelo príncipe.

Portanto, a dominação pode justificar-se em diversos motivos de submissão ou princípios de autoridade. Weber estudou as estruturas de dominação especialmente caracterizadas em duas formas básicas: a burocrática e a carismática. Quanto à dominação carismática, pode-se dizer que ela está centrada na crença da santidade, do heroísmo ou exemplaridade (arquétipo) de determinada personalidade e nas ordenações ou regras por ela criadas ou reveladas por meio da devoção, como dizia Weber. A forma de dominação burocrática é caracterizada pela autoridade que encarna o direito, onde a luta pelo poder é a luta pela influência decisiva sobre as ordenações jurídicas que são instituídas.

\section{O Tipo Ideal da Burocracia Weberiana: uma Incursão na Teoria das Organizações}

O traço marcante da obra de Weber com relação ao estudo das sociedades ocidentais contemporâneas pressupõe que o mundo tenda inexoravelmente para a racionalização em todas as esferas da vida social. A burocracia, portanto, representa o meio por intermédio do qual esta tendência à racionalização se mantém presente nas sociedades ocidentais. Weber afirma que em todas as instituições sociais, tenham elas fins materiais ou ideais, a burocracia está presente e estas instituições se organizam e atuam por intermédio de um instrumento cada vez mais universal e eficaz do exercício da dominação, que é a própria burocracia.

Como foi dito anteriormente, a sociologia weberiana distingue três tipos de dominação legítima na sociedade: a tradicional, a carismática e a racional ou legal. A dominação racional ou legal, para a qual tendem os dois outros tipos, dáse quando o sistema de leis e normas aplicadas judicial ou administrativamente de acordo com determinados princípios, vale para todos os membros do grupo social. A organização fundamenta-se em normas e a racionalização tende a reduzir a importância relativa de outras influências (riqueza, costumes, parentesco e amigos) e a substitui por leis ou regulamentos de administração.

É importante ressaltar que a razão fundamental para que Weber estudasse o tipo ideal da burocracia, foi a preocupação com a sua expansão no sistema social, representando, no seu entendimento, grande perigo para o homem. Weber entendia a burocracia como um tipo de poder, igualada à organização, considerada como um sistema racional onde a divisão do trabalho se processa racionalmente em função dos fins propostos, no qual predomina a ação racional burocrática que demanda coerência da relação entre meios e fins (objetivos estabelecidos). Além disso, ele entendia que a burocracia implicava predomínio do formalismo, da 
existência de normas escritas, da estrutura hierárquica, da divisão horizontal e vertical do trabalho e, finalmente, da impessoalidade do recrutamento de pessoal.

O tipo do burocrata na análise weberiana pressupõe, por um lado, um indivíduo que age em cooperação com os outros, cujo ofício é separado de sua vida familiar e pessoal, regulamentado por mandatos, exigência de competência e conhecimento, bem como perícia. Por outro lado, a organização burocrática é hierárquica, a admissão e ascensão profissional se dão por meio de critérios objetivos. Nela predomina a dominação racional-legal e são eliminados todos os elementos irracionais, não passíveis de cálculo. O estudo de Weber sobre o tipo ideal da burocracia evidencia que o seu desenvolvimento não implica uma democratização ativa, podendo colocar-se a serviço de diversos interesses de dominação, o que o leva a propor estudos particularizados para a busca do sentido da burocratização, embora reconheça que o fenômeno burocrático e o cesarismo sejam, de certo modo, o destino inevitável de um povo governado num Estado de massas.

No campo da teoria das organizações e, em particular, nas ciências da administração, os estudos de Weber sobre a burocracia representam um marco histórico, pois foi esse sociólogo o sistematizador do trabalho geral mais importante a respeito do tema, cuja repercussão provocou reflexões e debates sobre as organizações em geral, levantando questões fundamentais sobre sua natureza, padrões de racionalidade, caráter instrumental da burocracia, o papel da especialização, separação do administrador dos meios administração, fidelidade impessoal ao cargo e até mesmo aspectos relativos à remuneração. Weber se tornou, na verdade, um dos principais responsáveis pelo salto qualitativo na evolução do conhecimento sobre a teoria da administração, na medida em que encaminhou suas idéias por meio do tipo ideal da burocracia, na direção da sociologia da organização. O modelo weberiano de estudo da burocracia é considerado o ponto de partida para os sociólogos e cientistas políticos no estudo das organizações. Weber é tido como o precursor do estruturalismo fenomenológico nas teoria das organizações. A partir da sua abordagem, foi possível fazer a síntese ou a fusão da organização formal com a informal (tipo ideal das relações sociais), que representa a base fundamental do estruturalismo na administração.

\section{Conclusões}

O entendimento das relações sociais como um campo fértil de múltiplas facetas, sempre apresenta ao estudioso novas perspectivas de análise quanto à questão 
social. O estudo de sociedades cada vez mais complexas implica na adoção de lógicas e modelos sem, contudo, jamais abandonar o conceito de dominação como parte integrante das relações sociais. A variedade de possibilidades e temas abertos pela obra de Weber nos permite, sem exageros, considerá-lo um clássico no estudo da sociologia moderna.

Ao longo da história da teoria da administração, vários têm sido os posicionamentos com relação ao tipo ideal de burocracia. Entendida como sendo uma maneira consciente de organizar pessoas e atividades na busca de objetivos específicos, a burocracia enfatiza a organização racional e eficiente em função destes objetivos. Já há algum tempo, muitos críticos de Weber têm procurado atribuir à burocracia e ao modo burocrático (tipo ideal) a principal responsabilidade pelos problemas enfrentados pelas empresas privadas e principalmente pelas estatais, que são tidas como eminentemente burocráticas. A burocracia passou, assim, a ser considerada como a causa máter de todos os problemas que impedem o funcionamento adequado, eficiente e eficaz, das organizações, tais como bloqueio e inibição da criatividade dos empregados, atraso na tomada de decisões importantes, aumento da papelada por meio da utilização de documentos desnecessários ou inúteis etc. O fato é que não faltam críticos ao modelo (tipo ideal) da burocracia criado por Weber. Entretanto, a maioria dos problemas que efetivamente ocorrem no processo administrativo das mais diversas organizações não invalida, de forma alguma, a adoção do modelo weberiano, pois os erros não estão no modelo, mas no modo ineficiente pelo qual ele foi introduzido ao longo do tempo nas organizações. Toda organização deve estabelecer para si mesma objetivos e padrões de desempenho a alcançar e as normas, registros e controles têm como finalidade principal auxiliar no atingimento dessas metas.

Evidências têm mostrado que as tendências à informatização nas várias áreas das atividades humanas (comércio, indústria, sistema financeiro, Estado etc) podem ser analisadas com sucesso aplicando-se os conceitos weberianos de burocratização e racionalização. Nos últimos anos, a teoria da administração tem incorporado novas propostas de ação, mediante o surgimento de novas tecnologias gerenciais, cujas formas de viabilização passam por processo de qualidade total, reengenharia, organização de aprendizagem, downsizing, network e outros. Porém, na essência, a organização mantém e manifesta as formas de dominação analisadas magistralmente por Weber, perpetuadas por meio da ideologia disseminada nos programas de treinamento e desenvolvimento de recursos humanos.

Se, por um lado, é possível estabelecer nexos causais entre as formas de dominação atualmente manifestadas (ou camufladas) dentro e fora das organizações, na tentativa de compreender (decifrar) o sentido da ação administrativa (social) dos gerentes 
profissionais (tipos ideais), por outro lado, para a compreensão deste sentido, podemos aplicar a metodologia weberiana, atentando para o fato de que o sujeito da ação não é mais o capitalista proprietário (dono) e sim o gerente profissional (tipo ideal de burocrata) contratado como seu preposto.

Aprofundando mais a questão da relação entre as formas de dominação (pensamento weberiano) e as novas formas de organização e gestão, pode-se fazer uma leitura crítica das práticas sociais presentes nas organizações, levandose em consideração três dimensões fundamentais apontadas por Srour (1999): econômica, política e simbólica. Na dimensão econômica, os fenômenos organizacionais são abordados em seus aspectos racionais que, embora manifestem a intenção de analisá-los de forma independente da vontade social, acabam por promover uma adaptação do conjunto organizacional à vontade do capital, deixando intencionalmente de lado a relação capital versus trabalho, ocultando o conflito e tornando-se veículo de manutenção da ideologia dominante.

A dimensão econômica de análise funciona como legitimadora da distribuição de poder, manifestada por intermédio de novas tecnologias de gestão anteriormente referidas. Como exemplo, pode-se citar a gestão participativa, a co-gestão e as equipes autônomas, utilizadas nas organizações para, em última análise, legitimar as relações de poder.

Quanto à dimensão política, observa-se uma disputa de interesses e pressões com o propósito de satisfazer alguns interesses em detrimento de outros, o que faz com que algumas decisões tomadas se tornem imperativas como ocorre, por exemplo, em organizações que praticam a reengenharia ou o downsizing, onde os agentes organizacionais medem força na disputa de cargos e funções dentro da estrutura organizacional. Assim, proprietários e gestores formam, por um lado, a chamada coalizão dominante e, por outro, os trabalhadores opõem resistências, reivindicando participação nas decisões e nos resultados, ao mesmo tempo em que clientes e fornecedores, investidores, autoridades, sindicatos, associações e comunidades tendem a funcionar como sustentáculos neste jogo de poder.

Tal como ocorre nas dimensões anteriores, a dimensão simbólica também possui capacidade de intervir na realidade organizacional. Assim, esta dimensão fundamenta-se num processo de indução, levando os atores organizacionais a fazer o que é julgado correto ou conveniente, sem o uso da força. Trata-se da influência baseada em algum conhecimento ou saber especial, visando a convencer os outros, persuadindo-os a alterar suas concepções e convicções. Esta dimensão baseia-se ainda na capacidade de inculcar idéias, transmitir propósitos, inspirar valores, induzir opiniões, aliciar etc. Pode-se citar como exemplo a tecnologia de gestão, que utiliza alguns dos elementos da dimensão simbólica nos processos de 
TQC (Total Quality Control), bem como as redes organizacionais, onde se destacam a persuasão racional e o convencimento.

Como ficou evidenciado nas três dimensões descritas, ainda prevalece no seio das organizações a dicotomia entre valores e fins. Assim, as práticas atuais de gestão empresarial têm como objetivo implícito a regulação do conflito entre capital e trabalho, muitas vezes camuflado por intermédio de ações desenvolvidas que reforçam a dominação da ideologia organizacional sobre as pessoas. Portanto, os princípios do paradigma weberiano da ação social, que visa à compreensão do sentido dessa dominação refletida nas práticas de gestão empresarial, sugerem debates e conversações no âmbito da teoria organizacional (Reed, 1998).

Enfim, o que se constata na realidade é a presença de um discurso novo legitimado por práticas de gestão empresarial ditas modernas, mas que, em essência, demonstram a predominância dos velhos conceitos burocráticos, que se manifestam sob nova e pretensiosa forma de ideologia.

Ressalte-se, ainda, que não era preocupação de Weber estabelecer uma definição para as organizações e tampouco padronizar procedimentos a serem seguidos por elas. O seu tipo ideal (burocracia) não tem a pretensão de ser um modelo prescritivo. Trata-se de uma abstração descritiva, um esquema que sintetiza os pontos comuns à maioria das organizações formais modernas, em que ele procurou desenvolver a base, o alicerce formal-legal sobre o qual as organizações se assentam.

\section{ReferênCIAS Bibliográficas}

ALEXANDER, J. C.

Max Weber: la théorie de la racionalization et le marxisme, sociologie et société. [S.n.], v. XIV, n. 2, p. 33-43, 1982.

CHIAVENATO, I.

Teoria geral da administração. São Paulo: McGrawHill, 1987.

\section{COHN, G.}

Crítica e resignação: fundamentos da sociologia de Max Weber. São Paulo: T. A. Queiróz, 1979.
COLLIOT-THÉLÈNE, C.

Max Weber et l'histoire. Paris: Presses Universitaires de France, 1995.

DILTHEY, W.

Sistema da ética. São Paulo: Ícone, 1994.

\section{DOMINGUES, I.}

Notas de aulas da FAFICH. Belo Horizonte, 1999. 
FREUND, J.

Sociologia de Max Weber. Rio de Janeiro: Forense-Universitária, 1975.

\section{MARX, K.}

El capital: critica de la economía política. Buenos Aires: Cartago, 1973.

\section{MEREUX, C.}

Weber et la question de l'ideologie, sociologie et sociétés. [S.n.], v. XIV, n. 2, p. 9-31, 1992.

QUINTANEIRO, T. et al.

Um toque de clássicos. Belo Horizonte: UFMG, 1999.

REED, M.

Teorização organizacional: um campo historicamente contestado. In: CLEGG, S. R.; HARDY, C.; NORD, W. Handbook de estudos organizacionais. São Paulo: Atlas, 1998.

RICKERT, H.

Ciência cultural y ciência natural. Buenos Aires: Spaza, Calte, 1943.
RICOEUR, P.

Do texto à ação: ensaios de hermenêutica. [S.l.]: Porto, 19-.

SROUR, R.

Poder, cultura e ética nas organizações. Rio de Janeiro: Campus, 1998.

TRAGTENBERG, M.

Burocracia e ideologia. São Paulo: Ática, 1980.

WEBER, M.

Ensaios de sociologia. Rio de Janeiro: Zahar Editores, 1979.

Economía y sociedad. México: Fondo de Cultura, 1984.

Conceitos sociológicos fundamentais: metodologia das ciências sociais. Campinas: Cortez/Unicamp, 1992.

A ética protestante e o espírito do capitalismo. São Paulo: Pioneira, 1997. 